\title{
Text mining in a literature review of urothelial cancer using topic model
}

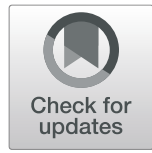

Hsuan-Jen Lin ${ }^{1,2,3+}$, Phillip C.-Y. Sheu ${ }^{1,4}$, Jeffrey J. P. Tsai ${ }^{1}$, Charles C. N. Wang ${ }^{1+}$ and Che-Yi Chou ${ }^{2,3,5,6^{*}}$ (D)

\begin{abstract}
Background: Urothelial cancer (UC) includes carcinomas of the bladder, ureters, and renal pelvis. New treatments and biomarkers of UC emerged in this decade. To identify the key information in a vast amount of literature can be challenging. In this study, we use text mining to explore UC publications to identify important information that may lead to new research directions.

Method: We used topic modeling to analyze the titles and abstracts of 29,883 articles of UC from Pubmed, Web of Science, and Embase in Mar 2020. We applied latent Dirichlet allocation modeling to extract 15 topics and conducted trend analysis. Gene ontology term enrichment analysis and Kyoto encyclopedia of genes and genomes pathway analysis were performed to identify UC related pathways.

Results: There was a growing trend regarding UC treatment especially immune checkpoint therapy but not the staging of UC. The risk factors of UC carried in different countries such as cigarette smoking in the United State and aristolochic acid in Taiwan and China. GMCSF, IL-5, Syndecan-1, ErbB receptor, integrin, c-Met, and TRAIL signaling pathways are the most relevant biological pathway associated with UC.

Conclusions: The risk factors of UC may be dependent on the countries and GMCSF, IL-5, Syndecan-1, ErbB receptor, integrin, c-Met, and TRAIL signaling pathways are the most relevant biological pathway associated with UC. These findings may provide further UC research directions.
\end{abstract}

Keywords: Urothelial carcinoma, Text mining, Topic modeling, LDA2vec, Research trends

\section{Background}

Urothelial carcinoma (UC) also known as transitional cell carcinoma includes carcinomas of the bladder, ureters, renal pelvis. UC is the fourth common cancer in men [1]. Risk factors of UC include cigarette smoking [2], chronic urinary tract inflammation, analgesics abuse, exposure to arylamines in the organic chemical, rubber, and paint and dye industries [3], Balkan nephropathy [4], chlorinated drinking water [5], arsenic-contaminated drink water [6], radiotherapy [7], and cyclophosphamide

\footnotetext{
* Correspondence: cychou.chou@gmail.com

${ }^{\dagger}$ Hsuan-Jen Lin and Charles C. N. Wang contributed equally to this work. ${ }^{2}$ Division of Nephrology, Asia University Hospital, Taichung, Taiwan

${ }^{3}$ Kidney Institute and Division of Nephrology, China Medical University Hospital, Taichung, Taiwan

Full list of author information is available at the end of the article
}

[8]. Non-muscle invasive bladder UC can be treated using transurethral bladder tumor resection and intravesical therapy [9]. Muscle-invasive bladder cancer is associated with a poor prognosis and is treated with neoadjuvant chemotherapy followed by cystectomy [10]. New treatment for UC such as immune checkpoint inhibitors is used for advanced and metastatic UC [11].

There is a large volume of publications on UC. Traditional ways of literature review tend to be timeconsuming and labor-intensive. Machine-learning-based literature mining may analyze large collections of documents, identifies patterns in a dataset using statistical and computational methods, make predictions based on the discovered patterns, and minimizes human interventions. Machine learning has been used in biomedical informatics research and early prediction of treatment

(c) The Author(s). 2020 Open Access This article is licensed under a Creative Commons Attribution 4.0 International License, which permits use, sharing, adaptation, distribution and reproduction in any medium or format, as long as you give appropriate credit to the original author(s) and the source, provide a link to the Creative Commons licence, and indicate if changes were made. The images or other third party material in this article are included in the article's Creative Commons licence, unless indicated otherwise in a credit line to the material. If material is not included in the article's Creative Commons licence and your intended use is not permitted by statutory regulation or exceeds the permitted use, you will need to obtain permission directly from the copyright holder. To view a copy of this licence, visit http://creativecommons.org/licenses/by/4.0/. The Creative Commons Public Domain Dedication waiver (http://creativecommons.org/publicdomain/zero/1.0/) applies to the data made available in this article, unless otherwise stated in a credit line to the data. 
outcomes. Literature mining using machine learning is useful in summarizing key research themes and trends [12]. A topic model is a probability-based text mining approach to identify the topics and has been applied to literary analysis in many research fields [13]. In this study, we extract a set of topics from the abstract of UC using a topic model, analyze the dynamics of topics, and explore the biological pathways associated with UC.

\section{Methods}

\section{Data set}

We used the keyword "urothelial cancer" to search abstract from PubMed, Web of science, and Embase in Mar 2020. Fourteen thousand four hundred forty-three abstracts were obtained from Pubmed, 14,390 from Web of Science, and 24,110 from Embase. A total of 29,883 abstracts were analyzed after the removal of the duplicated ones. The title and abstract of each article were extracted and then combined into a single string. The keywords assigned by authors were not included [14]. The general words (such as background, aim, objective, purpose, method, result, conclusion), stop words, numerical digits, punctuation, and symbols were removed.

\section{Topic modeling}

Latent Dirichlet Allocation (LDA) is a type of topic modeling. Lda2vec is an extension of word2vec and learns word, document, and topic vectors. LDA learns the powerful word representations in word2vec and constructs a human-interpretable LDA document. The LDA document is obtained by modifying the skip-gram variant. In the original skip-gram method, the model is trained to predict context words based on a pivot word. Lda2vec goes one step beyond the paragraph approach by working with document-sized text fragments and decomposing the document into two different components - a document weight vector and a topic matrix. The document weight vector represents the percentage of the different topics and the topic matrix consists of different topic vectors. A context vector is constructed by combining the different topic vectors in a document [15].

Lda2vec is an unsupervised text mining method and to determine the optimal number of topics is critical. There is no best way of choosing the optimal number of topics [16]. The perplexity measure may estimate the optimal number of topics, its result is difficult to interpret. The optimal number of topics is usually decided by researchers. We tested Lda2vec with 10, 15, and 20 topics, and compared the similarity and difference of content of topics obtained using the different models to determine the optimal number of topics.

\section{Visualization of topics}

For visualization of the content of topics, the most probable words to convey a topic meaning were listed with the RGB color model, an additive color model in which red $(R)$, green $(G)$, and blue (B) light are added together in various parameters to reproduce a broad spectrum of colors. The parameters of R, G, and B are all inversely proportional to the normalized probability of words, and the color is shaded in greyscale from black to white. The higher color depth indicates a higher probability. The RGB color model was plotted with python (wordcloud package version 1.6.0). The word clouds were also plotted to demonstrate the distribution of vocabularies over each topic. To make the visualization clear, we combined the singular and the plural forms of a word as one

Table 1 The most probable keywords in 15 topics of LDA2vec

\begin{tabular}{|c|c|c|}
\hline T1 & Severity & invasive, muscle, bladder, high, cancer, tumor, significant, Cl, overall, lower \\
\hline $\mathrm{T} 2$ & Treatment & treatment, therapy, management, review, evidence, related, standard, malignancy, use, development \\
\hline T3 & Survival & recurrence, survival, ci, free, cancer, specific, cox, overall, ratio, significant \\
\hline T4 & Urine & mean, urine, specimen, negative, invasion, value, sample, objective, age, higher \\
\hline T5 & Bladder & urinary, tract, reported, bladder, significant, urothelial, review, lower, among, revealed \\
\hline T6 & Upper urinary tract & UC, urothelial, carcinoma, higher, negative, upper, within, tract, tumor, characteristic \\
\hline T7 & Gene & expression, gene, tumor, tissue, normal, carcinoma, human, growth, urothelial, marker \\
\hline T8 & Lower urinary tract & bladder, cancer, effect, treatment, tumor, transurethral, among, detected, lower, number \\
\hline T9 & Chemotherapy & chemotherapy, median, advanced, treatment, treated, survival, effect, carcinoma, received, therapy \\
\hline T10 & Surgery & tumor, carcinoma, bladder, transitional, resection, detected, transurethral, urothelial, recurrence, malignant \\
\hline T11 & Patients' characteristics & male, higher, range, analyzed, age, among, characteristic, transitional, objective, effect \\
\hline T12 & Grade & carcinoma, urothelial, grade, high, low, lesion, biopsy, negative, reported, specimen \\
\hline T13 & Radical cystectomy & cystectomy, radical, surgery, bladder, treated, among, significant, treatment, carcinoma, age \\
\hline T14 & Lymph Node metastasis & metastasis, node, lymph, surgical, metastatic, cancer, survival, range, carcinoma, radical \\
\hline T15 & Nephroureterectomy & tumour, renal, upper, tract, carcinoma, nephroureterectomy, urothelial, surgery, lower, grade \\
\hline
\end{tabular}

UC urothelial cancer 


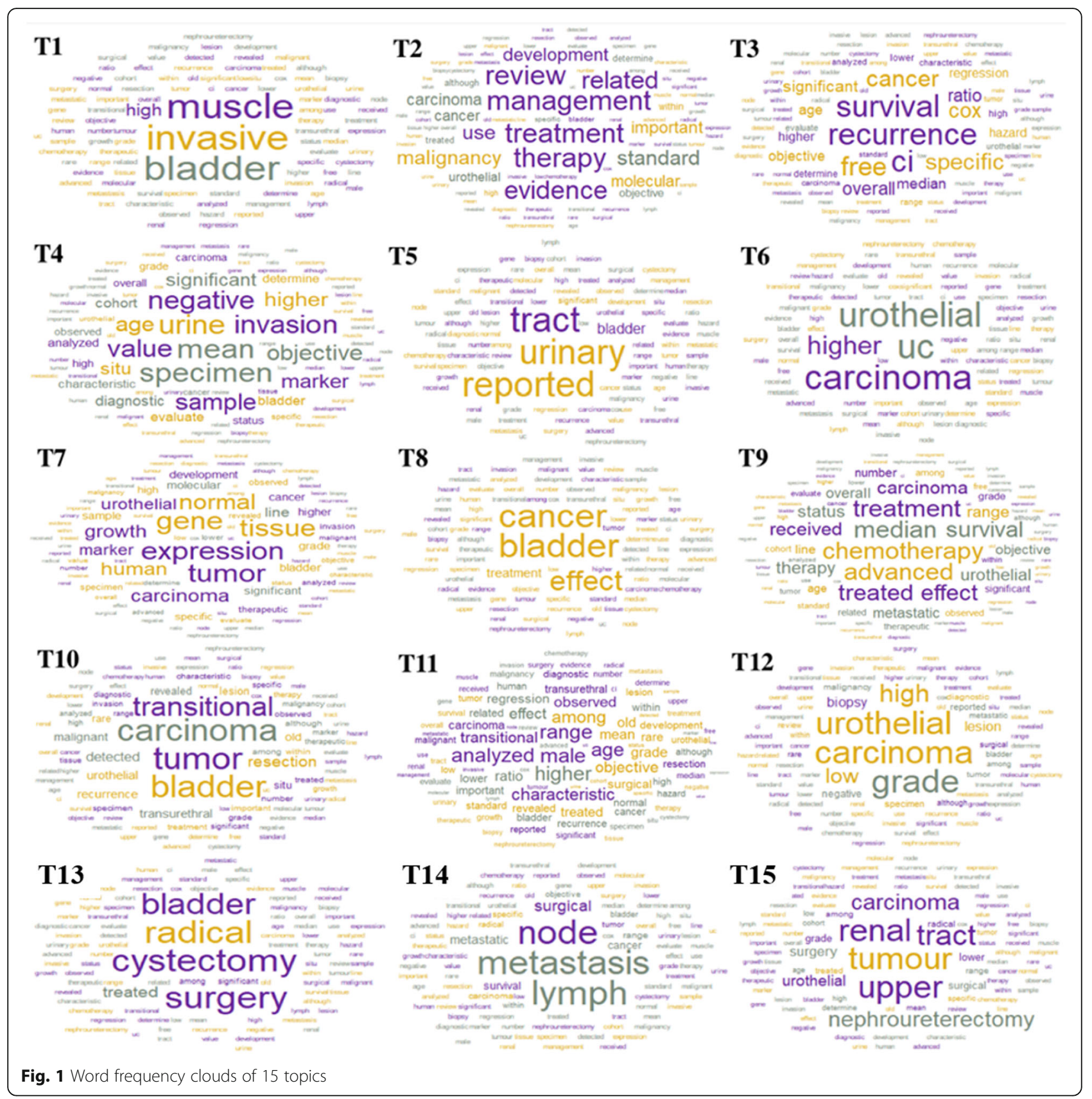

word if both forms were listed in the top 20 probable words for a given topic. The topics were individually presented as an unstructured set of word clouds, and the word size is proportional to the probability of the word within a topic, $P$ (word $\mid$ topic).

\section{Gene ontology and pathway enrichment analysis}

To investigate a comprehensive set of functional annotations of the hub gene. Gene Ontology (GO) term enrichment analysis and Kyoto Encyclopedia of Genes and Genomes (KEGG) pathway analysis were performed by using the "FunRich" [17]. FunRich is a functional enrichment and interaction network analysis tool, which allowed the updating database for performing functional enrichment analysis. GO enrichment analysis and KEGG pathway analysis were performed with the FunRich functional enrichment analysis tool (version 3.1.3). A $p$-value of $<0.05$ was considered significant [18].

\section{Results}

We explored the top 10, 15, 30 keys words and selected the top 15 keywords. LDA discovered separate and 


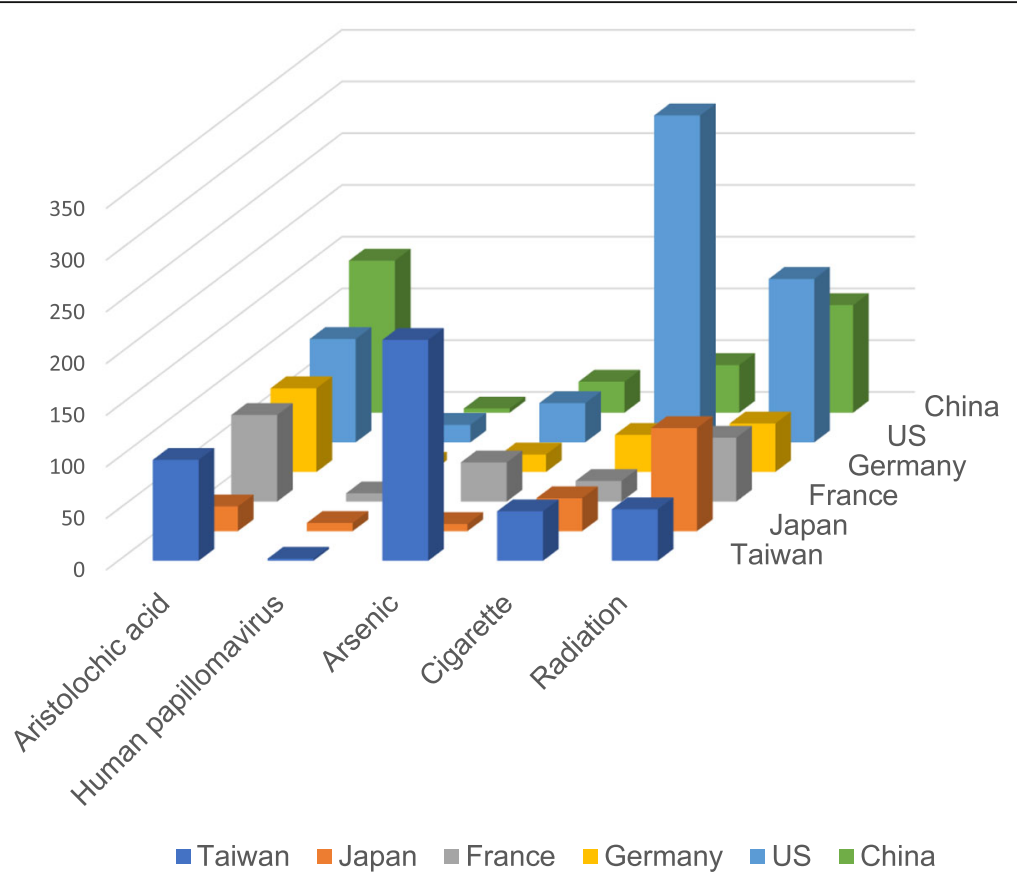

Fig. 2 The number of publications according to risk factors and countries

relative definite issues, the location of $\mathrm{UC}$ ( $\mathrm{T} 5, \mathrm{~T} 6, \mathrm{~T} 8$, $\mathrm{T} 15)$, gene (T7), treatment (T2, T9, T10, T13, T15), and severity (T1, T4, T12, T14). Some of the topics are related. For example, the gene expression (T7) and tumor grade (T12) are associated with the decision of chemotherapy (T9), surgery (T10, T15), and survival (T3). The keywords in each topic are shown in Table 1. The word clouds of 15 topics (Fig. 1) provide better visualization of the topics. The larger font size depth indicates a higher probability of the word. Muscle, invasive, and bladder were the most frequent words in $\mathrm{T} 1$ because $\mathrm{T} 1$ was about the severity of UC. Muscle invasion of the urinary bladder was a key characteristic of advanced UC. Higher, urothelial, and carcinoma were the most frequent words that appeared in $\mathrm{T} 6$ because $\mathrm{T} 6$ is about upper urinary tract UC. As T14 is about metastatic UC, the most frequent words were metastasis, lymph, and node.

There was an association between risk factors of UC and countries in the analysis of 13,725 abstracts (Fig. 2). The top 10 publications were from the United States, Taiwan, China, Germany, Japan, France, India, Italy, Span, and Iran. The top 10 risk factors of UC were cigarette, radiation, arsenic, aristolochic acid, human papillomavirus, chronic cystitis, cyclophosphamide, aromatic amines, coffee, and tea. Most of the studies reported the association between UC and aristolochic acid were from the United States, Taiwan, and China. Arsenic associated publications were mainly from Taiwan. Most publications focusing on risk factors such as cigarettes, human papillomavirus, and radiation are from the United States.

\section{Gene ontology and pathway enrichment analysis}

A total of 15,491 abstracts were associated with genes related to UC and we identified the pathway according to the identified gene. The top ten pathways associated with UC were granulocyte-macrophage colonystimulating factor (GMCSF)-medicated signal events, interleukin (IL) 5-mediated signaling events, ErbB receptor signaling network, Syndecan-1-mediated signaling events, TNF-related apoptosis-inducing ligand (TRAIL) signaling pathway, Signaling events mediated by Hepatocyte Growth Factor Receptor (c-Met), Glypican pathway, Proteoglycan syndecan-mediated signaling events, Beta1 integrin cell-surface interactions, and Integrin family cell surface interactions (Fig. 3). The percentage of the gene in the publications ranged from 40.5 to $43.3 \%$. The pathways from top to bottom are listed according to the $P$-values of the hypergeometric test.

\section{Discussions}

In this text mining assisted literature review of UC, we found an increasing trend of publications regarding treatment, survival, and gene. A decreasing trend of publications regarding upper urinary tract UC, radical cystectomy, and lymph node metastasis was also observed. Immune checkpoint therapy is the hottest topic in the 
Biological pathway for New Set

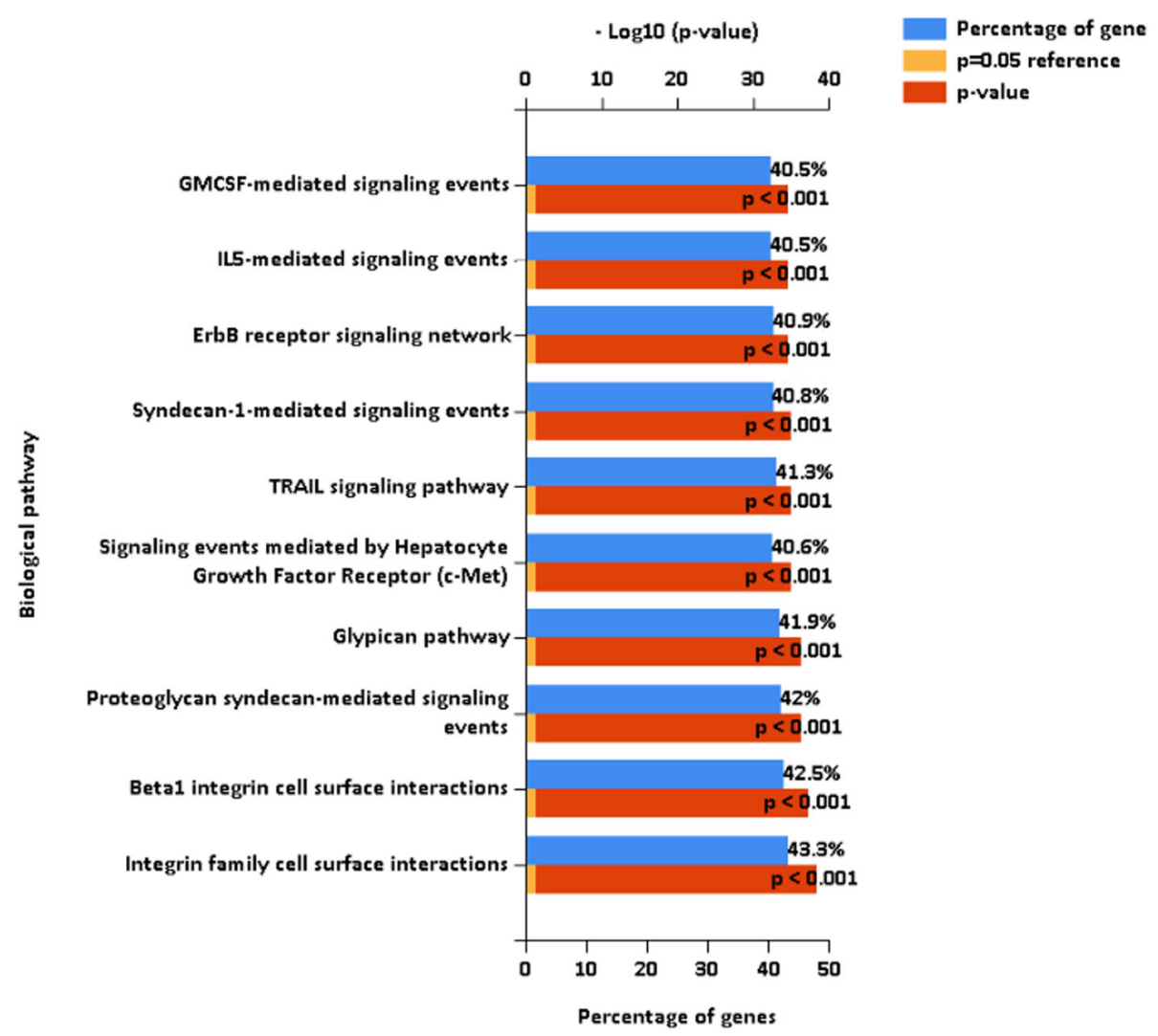

Fig. 3 The top ten pathways in which urothelial cancer was significantly involved (ranked by p-value using the FunRich 3.0 software). A p-value $<0.05$ was regarded as significant

UC treatment. The majority of the publications are from the United States, China, Japan, Taiwan, Germany, Italy, and France. Cigarette smoking and aromatic amines are commonly reported risk factors $[19,20]$, followed by radiation, arsenic, aristolochic acid, and human papillomavirus. Tea and coffee [21-23] have been also extensively studied in their association with UC and they have a neutral or beneficial effect on UC. Aristolochic acid is commonly used for urinary tract and respiratory tract infection in traditional Chinese medicine can be associated with renal failure and UC [24-26]. Most of the publications about aristolochic acid are from Taiwan and China. But many reports were from the United States, Germany, and France. This may suggest that exposure to aristolochic acid is common in Taiwan and China but is not limited to these countries. The difference in risk factors among different countries may suggest racial differences in cancer susceptibility and the importance of the environmental factor in the pathogenesis of UC.

The top ten pathways identified may help to explore new treatment for UC. One of the examples is
Mycobacterium bovis bacillus Calmette-Guérin. Mycobacterium bovis bacillus Calmette-Guérin has been used as an effective treatment for UC because it activates the TRAIL signaling pathway that leads to tumor necrosis through the immune response [27]. GMCSF is associated with aggressive tumor cell growth [28]. IL5mediated signaling and Syndecan-1-mediated signaling [29] enhances cancer cell migration and invasion [30]. ErbB receptor signaling [30] and cell-surface integrin [31] increases cancer cell resistance to chemotherapy. Hepatocyte Growth Factor Receptor (c-Met) [32] and glypican [33] are linked to the clinical outcomes. Medications that target these pathways may be used to treat $\mathrm{UC}$.

There are some limitations to this study. First, only results from Pubmed were analyzed and the language is limited to English. This may lead to selection bias. Second, the analysis was conducted based on the extracted abstracts but not the full texts. More information may be obtained if we apply analysis on full texts. Third, we used LDA to extract articles. LDA was the concept of "bag of words" rather than the order of words. When a 
sentence was divided into separate words, it became meaningless or lost the original meaning. Forth, the frequency of words was presented but the frequency of the words may not necessarily stand for their significance.

\section{Conclusion}

In this paper, we have presented an empirical study by utilizing LDA modeling to discover major research topics of UC. We analyzed the dynamics and intellectual structure of topics. We found growing researches on the treatment but not cancer staging. Cigarette smoking and arsenic are the most commonly reported risk factors worldwide and there is an association between UC risk factors and countries. GMCSF, IL-5, Syndecan-1, ErbB receptor, integrin, $\mathrm{c}-\mathrm{Met}$, and TRAIL signaling pathways are the top biological pathways associated with UC. The study provides a better understanding of the trends of $\mathrm{UC}$ research and potential future research directions.

\section{Abbreviations}

UC: Urothelial cancer; GMCSF: Granulocyte-macrophage colony-stimulating factor; IL-5: Interleukin-5; ErbB: Epidermal growth factor receptor family; cMet: Tyrosine-protein kinase Met; TRAIL: TNF-related apoptosis-inducing ligand; LDA: Latent dirichlet allocation

\section{Acknowledgments}

None.

\section{Authors' contributions}

$\mathrm{CN}$ analyzed and interpreted the data. $\mathrm{HJ}$ and $\mathrm{CY}$ (Chou) were major contributors in writing the manuscript. CY (Sheu) and JP supervised the study and provided critical suggestions to the study. All authors read and approved the final manuscript.

\section{Funding}

The study is partially supported by the grant number ASIA-107-AUH-01. The funders had no role in study design, data collection, and analysis, decision to publish, or preparation of the manuscript.

\section{Availability of data and materials}

The datasets used and/or analysed during the current study are available from the corresponding author on reasonable request.

\section{Ethics approval and consent to participate}

Not applicable.

\section{Consent for publication}

Not applicable.

\section{Competing interests}

The authors declare that they have no competing interests.

\section{Author details}

'Department of Biomedical Informatics, Asia University, 500, Lioufeng Rd., Wufeng, Taichung, Taiwan. '2Division of Nephrology, Asia University Hospital, Taichung, Taiwan. ${ }^{3}$ Kidney Institute and Division of Nephrology, China Medical University Hospital, Taichung, Taiwan. ${ }^{4}$ Department of Electrical Engineering and Computer Science, University of California, Irvine, 5200 Engineering Hall, Irvine, CA 92697, USA. ${ }^{5}$ Department of Post-baccalaureate Veterinary Medicine, Asia University, Taichung, Taiwan. ${ }^{6}$ Department of internal medicine, Asia University Hospital, Taichung 413, Taiwan.
Received: 20 August 2019 Accepted: 5 May 2020

Published online: 24 May 2020

\section{References}

1. Siegel RL, Miller KD, Jemal A. Cancer statistics, 2018. CA Cancer J Clin. 2018; 68(1):7-30.

2. Freedman ND, Silverman DT, Hollenbeck AR, Schatzkin A, Abnet CC Association between smoking and risk of bladder cancer among men and women. JAMA. 2011;306(7):737-45.

3. Burger M, Catto JW, Dalbagni G, Grossman HB, Herr H, Karakiewicz P, Kassouf W, Kiemeney LA, La Vecchia C, Shariat S, et al. Epidemiology and risk factors of urothelial bladder cancer. Eur Urol. 2013;63(2):234-41.

4. Lai MN, Wang SM, Chen PC, Chen YY, Wang JD. Population-based casecontrol study of Chinese herbal products containing aristolochic acid and urinary tract cancer risk. J Natl Cancer Inst. 2010;102(3):179-86.

5. Villanueva CM, Fernandez F, Malats N, Grimalt JO, Kogevinas M. Metaanalysis of studies on individual consumption of chlorinated drinking water and bladder cancer. J Epidemiol Community Health. 2003;57(3):166-73.

6. Marshall G, Ferreccio C, Yuan Y, Bates MN, Steinmaus C, Selvin S, Liaw J, Smith AH. Fifty-year study of lung and bladder cancer mortality in Chile related to arsenic in drinking water. J Natl Cancer Inst. 2007;99(12):920-8.

7. Sandhu JS, Vickers AJ, Bochner B, Donat SM, Herr HW, Dalbagni G. Clinical characteristics of bladder cancer in patients previously treated with radiation for prostate cancer. BJU Int. 2006:98(1):59-62.

8. Travis LB, Curtis RE, Glimelius B, Holowaty EJ, Van Leeuwen FE, Lynch CF, Hagenbeek A, Stovall M, Banks PM, Adami J, et al. Bladder and kidney cancer following cyclophosphamide therapy for non-Hodgkin's lymphoma. J Natl Cancer Inst. 1995;87(7):524-30.

9. Hall MC, Chang SS, Dalbagni G, Pruthi RS, Seigne JD, Skinner EC, Wolf JS Jr, Schellhammer PF. Guideline for the management of nonmuscle invasive bladder cancer (stages ta, T1, and tis): 2007 update. J Urol. 2007;178(6): 2314-30.

10. Giridhar KV, Kohli M. Management of Muscle-Invasive Urothelial Cancer and the emerging role of immunotherapy in advanced Urothelial Cancer. Mayo Clin Proc. 2017;92(10):1564-82.

11. Massari F, Di Nunno V, Cubelli M, Santoni M, Fiorentino M, Montironi R, Cheng L, Lopez-Beltran A, Battelli N, Ardizzoni A. Immune checkpoint inhibitors for metastatic bladder cancer. Cancer Treat Rev. 2018;64:11-20.

12. Jensen $\sqcup$, Saric J, Bork P. Literature mining for the biologist: from information retrieval to biological discovery. Nat Rev Genet. 2006;7(2):11929.

13. Wang SH, Ding Y, Zhao W, Huang YH, Perkins R, Zou W, Chen JJ. Text mining for identifying topics in the literatures about adolescent substance use and depression. BMC Public Health. 2016;16:279.

14. Syed $\mathrm{S}$, Weber $\mathrm{CT}$. Using machine learning to uncover latent research topics in fishery models. Rev Fish Sci Aquaculture. 2018;26(3):319-36.

15. Miao Y, Yu L, Blunsom P. Neural Variational Inference for Text Processing. Proceedings of The 33rd International Conference on Machine Learning, PMLR. 2016;48:1727-36.

16. Zhao W, Chen JJ, Perkins R, Liu Z, Ge W, Ding Y, Zou W. A heuristic approach to determine an appropriate number of topics in topic modeling. BMC Bioinformatics. 2015;16(Suppl 13):S8.

17. Benito-Martin A, Peinado H. FunRich proteomics software analysis, let the fun begin! Proteomics. 2015;15(15):2555-6.

18. Pathan M, Keerthikumar S, Ang CS, Gangoda L, Quek CY, Williamson NA Mouradov D, Sieber OM, Simpson RJ, Salim A, et al. FunRich: an open access standalone functional enrichment and interaction network analysis tool. Proteomics. 2015;15(15):2597-601.

19. Pelucchi C, Bosetti C, Negri E, Malvezzi M, La Vecchia C. Mechanisms of disease: the epidemiology of bladder cancer. Nat Clin Pract Urol. 2006;3(6): $327-40$.

20. Jiang X, Yuan JM, Skipper PL, Tannenbaum SR, Yu MC. Environmental tobacco smoke and bladder cancer risk in never smokers of Los Angeles County. Cancer Res. 2007;67(15):7540-5.

21. Yang CS, Maliakal P, Meng X. Inhibition of carcinogenesis by tea. Annu Rev Pharmacol Toxicol. 2002:42:25-54.

22. Qin J, Xie B, Mao Q, Kong D, Lin Y, Zheng X. Tea consumption and risk of bladder cancer: a meta-analysis. World J Surg Oncol. 2012;10:172.

23. Weng H, Zeng XT, Li S, Kwong JS, Liu TZ, Wang XH. Tea consumption and risk of bladder Cancer: a dose-response meta-analysis. Front Physiol. 2016;7: 693. 
24. Yang HY, Chen PC, Wang JD. Chinese herbs containing aristolochic acid associated with renal failure and urothelial carcinoma: a review from epidemiologic observations to causal inference. Biomed Res Int. 2014;2014: 569325.

25. Witkowicz J. Aristolochic acid nephropathy. Przegl Lek. 2009;66(5):253-6.

26. Lai MN, Lai JN, Chen PC, Hsieh SC, Hu FC, Wang JD. Risks of kidney failure associated with consumption of herbal products containing mu Tong or Fangchi: a population-based case-control study. Am J Kidney Dis. 2010;55(3):507-18.

27. Rosevear HM, Lightfoot AJ, O'Donnell MA, Griffith TS. The role of neutrophils and TNF-related apoptosis-inducing ligand (TRAIL) in bacillus CalmetteGuerin (BCG) immunotherapy for urothelial carcinoma of the bladder. Cancer Metastasis Rev. 2009;28(3-4):345-53.

28. Hirasawa K, Kitamura T, Oka T, Matsushita H. Bladder tumor producing granulocyte colony-stimulating factor and parathyroid hormone related protein. J Urol. 2002;167(5):2130.

29. Shimada K, Nakamura M, De Velasco MA, Tanaka M, Ouji Y, Miyake M, Fujimoto K, Hirao K, Konishi N. Role of syndecan-1 (CD138) in cell survival of human urothelial carcinoma. Cancer Sci. 2010;101(1):155-60.

30. Lee EJ, Lee SJ, Kim S, Cho SC, Choi YH, Kim WJ, Moon SK. Interleukin-5 enhances the migration and invasion of bladder cancer cells via ERK1/2mediated MMP-9/NF-kappaB/AP-1 pathway: involvement of the P21WAF1 expression. Cell Signal. 2013;25(10):2025-38.

31. Faltas BM, Prandi D, Tagawa ST, Molina AM, Nanus DM, Sternberg C, Rosenberg J, Mosquera JM, Robinson B, Elemento O, et al. Clonal evolution of chemotherapy-resistant urothelial carcinoma. Nat Genet. 2016;48(12): 1490-9.

32. Comperat E, Roupret M, Chartier-Kastler E, Bitker MO, Richard F, Camparo P, Capron F, Cussenot O. Prognostic value of MET, RON and histoprognostic factors for urothelial carcinoma in the upper urinary tract. J Urol. 2008; 179(3):868-72 discussion 872.

33. Xylinas E, Cha EK, Khani F, Kluth LA, Rieken M, Volkmer BG, Hautmann R, Kufer R, Chen YT, Zerbib M, et al. Association of oncofetal protein expression with clinical outcomes in patients with urothelial carcinoma of the bladder. J Urol. 2014;191(3):830-41.

\section{Publisher's Note}

Springer Nature remains neutral with regard to jurisdictional claims in published maps and institutional affiliations.

Ready to submit your research? Choose BMC and benefit from:

- fast, convenient online submission

- thorough peer review by experienced researchers in your field

- rapid publication on acceptance

- support for research data, including large and complex data types

- gold Open Access which fosters wider collaboration and increased citations

- maximum visibility for your research: over $100 \mathrm{M}$ website views per year

At BMC, research is always in progress.

Learn more biomedcentral.com/submissions 